\title{
Validação do sistema de transporte e das dosagens de amostras biológicas enviadas para a central de um laboratório de grande porte
}

\author{
Transport system validation and analysis of biological samples sent to a central laboratory \\ Alexandre Gabriel Jr. '; Ana Amélia B. Silva²; Maria Cristina De Martino³; Wagner José Razvickas4; Regina Corrêa Silva \\ Ana Maria Viana ${ }^{6}$; Richard Couto Maurício ${ }^{7}$; Silmara Aparecida Leopoldino Santos ${ }^{8}$; Sérgio Tufik ${ }^{9}$
}

\begin{abstract}
unitermos
Transporte

Amostras biológicas

Temperatura

Análises Laboratoriais

\section{resumo}

A monitoração de vários interferentes nos resultados das análises clínicas laboratoriais originados do sistema de transporte de amostras biológicas de um posto de coleta para o local da fase analítica propriamente dita é de extrema importância. Com o objetivo de avaliar a estabilidade dos bioanalitos durante o transporte, os autores, neste trabalho, monitoraram a temperatura das caixas térmicas. Através de dispositivos medidores de temperatura (chips) introduzidos no interior de cada caixa térmica, observou-se que elas permaneceram climatizadas em torno de $13^{\circ}$ a $23^{\circ} \mathrm{C}$, simulando a temperatura ambiente por todo o percurso e tempo necessários. Compararam-se os resultados de análises clínicas laboratoriais das amostras biológicas sem transporte realizadas no laboratório de origem da coleta (Jundiaî) com os das mesmas amostras biológicas com transporte realizado na central em São Paulo. Inicialmente foram estudados os principais parâmetros bioquímicos e a coagulação do sangue, além da urinálise com bacteriologia. A análise estatística foi de concordância entre as duas médias através do coeficiente de correlação intraclasse e também pela técnica de Bland-Altman, na qual se observou que, entre os 29 analíticos estudados, 23 (79,3\%) apresentaram concordância boa a excelente; cinco $(17,2 \%)$, moderada a boa; e uma $(3,5 \%)$, fraca a moderada. Quanto às uroculturas, elas apresentaram $88 \%$ de concordância, portanto boa a excelente, e a urina I apresentou $94 \%$ de concordância na hematúria e $87,5 \%$ na leucocitúria, também boa a excelente. Os dados obtidos pelas correlações dos resultados das amostras e dos gráficos de temperatura emitidos pelos dispositivos registradores representaram indicadores de validação do sistema de transporte e das análises laboratoriais em até 16 horas após coleta do material, simulando um posto muito distante.
\end{abstract}

abstract

The results obtained from biological sample analysis may be affected by several factors, among them, the conditions of samples transportation from the site of collection to the central laboratory. The aim of this paper was to verify the stability of the samples submitted to the transportation process (from Jundiai to São Paulo) by comparing the results of 29 clinical laboratory parameters (including microbiology tests) on the same samples submitted or not to transportation. First, we verified the temperature inside a transportation box, during the routine the from Jundiai to São Paulo, by introducing a special chip able to register it continuously. We observed that the temperature inside the box was kept between $13^{\circ} \mathrm{C}$ and $23^{\circ} \mathrm{C}$ (similar to room temperature). After that, samples were collected in Jundiai and divided in two aliquots; one to be analysed at the laboratory in São Paulo. The methodology, apparatus and reagents used on the samples analysis were the same at both laboratories. The statistical analysis showed concordance between both averages trough correlation coefficient "intra-class" and by the "Blan-Altman methods". It was observed that among the 29 parameters: 23 (79,3\%) showed good to excellent. On the data from urinalysis we observed a good to excellent concordance in the urocult (88.0\%), and as well in the urine I analysis. The data obtained by the correlation between the laboratory results and the graphics of temperature registered by chip are strong indicative of validation of our laboratorial analysis and transportation system, up to 16 hours sample collection. key words

Transportation

Biological samples

Temperature

Laboratorial analysis

1. Médico patologista clínico; doutor em Medicina pela Universidade Federal de São Paulo (UNIFESP), diretor clínico da AFIP Medicina Laboratorial.

2. Engenheira; doutora em Bioestatística pela UNIFESP; professora da Universidade de São Paulo (USP).

3. Bióloga, coordenadora da Qualidade, Validação e Pesquisa da AFIP Medicina Laboratorial.

4. Administrador em Saúde; coordenador da Qualidade da AFIP Medicina Laboratorial.

5. Biomédica; mestre em Análises Clínicas; supervisora do setor de Bacteriologia da AFIP Medicina Laboratorial.

6. Supervisora do setor de Bioquímica da AFIP Medicina Laboratorial.

7. Supervisor da AFIP Medicina Laboratorial.

8. Biomédica; supervisora da AFIP Medicina Laboratorial.

9. Médico; professor titular do Departamento de Psicobiologia da UNIFESP; presidente da AFIP Medicina Laboratorial. 


\section{Introdução}

Já é amplamente conhecido que variações por diferentes parâmetros ambientais podem alterar sobremaneira os resultados de dosagens analíticas das amostras biológicas ${ }^{(12)}$. Durante o transporte, as amostras estão sujeitas à influência de tempo, temperatura, choques mecânicos, entre outras. Assim, é de fundamental importância avaliar a interferência do nosso sistema de transporte na qualidade dos resultados laboratoriais emitidos.

\section{Objetivo}

A finalidade deste trabalho é validar o sistema de transporte e demonstrar a sua influência na análise dos resultados dos exames que necessitam de transporte para a central de um laboratório de grande porte.

\section{Material}

\section{Amostras biológicas}

Foram coletadas quatro amostras em duplicata de 35 pacientes, aleatoriamente, que compareceram ao laboratório do Hospital São Vicente (Jundiaí, SP) em dois períodos (dias) não-consecutivos.

As amostras foram de sangue total: 1. sem anticoagulante, 2. com ácido etilenodiaminotetracético (EDTA), 3. com citrato de sódio, 4. com fluoreto de sódio.

Também foi coletada em duplicata, em frasco universal e estéril, amostra isolada de urina.

As primeiras amostras foram processadas no próprio laboratório do Hospital São Vicente, e as suas duplicatas foram enviadas para o laboratório central (São Paulo, SP).

\section{Análises laboratoriais, reagentes e equipamentos}

Determinações de glicose, colesterol, triglicérides e uréia foram analisadas pelo método enzimático calorimétrico utilizando-se reagente da Dialab Ges m.b.H e equipamento Opera Bayer.

O método cinético foi o escolhido para determinações de fósforo e creatinina com reagente da Synermed INT. INC. e equipamento Opera Bayer.

Parâmetros de cálcio e magnésio foram realizados com Labtest Diag.S. A e Wierner Laborat SAIC, respectivamente, em equipamento Opera Bayer;
E as enzimas aspartato alanina aminotransferase e aspartato aminotransferase (ALT/AST), fosfatase alcalina, gamaglutamiltransferase (GGT), desidrogenase lática (LDH), creatinoquinase (CK) e fração $\mathrm{MB}$ da creatinofosfoquinase (CK-MB), por método cinético enzimático, utilizando-se Dialab Ges.mb.H e o mesmo equipamento.

Para os parâmetros de coagulação tempo de protrombina (TP) e tempo parcial de tromboplastina ativada (TTPa) utilizaram-se reagente da Wiener Laborat. SAIC e Diag. Stago Inc. em equipamento Start - Bayer/STA Compact - Stago, enquanto que o fibrinogênio foi determinado com reagente Fibri-Test Diagnostica Stago Inc. no equipamento Start - Bayer/STA Compact - Stago.

Urina I e uroculturas foram realizadas de acordo com técnicas padronizadas e normas internacionais, seguindo as normas de boas práticas de laboratórios clínicos (BPLCs).

Todos os ensaios analíticos tiveram acompanhamento dos controles internos de qualidade.

\section{Método}

\section{Coleta e transporte}

Todas as amostras coletadas seguiram os padrões descritos nas normas de coleta segundo as BPLCs.

Após a coleta, as primeiras amostras foram transferidas para o laboratório clínico do próprio Hospital São Vicente (Jundiai), enquanto suas duplicatas foram acondicionadas para transporte via estrada de rodagem.

Em ambos os laboratórios (Jundiaí e São Paulo), todas as amostras foram submetidas à centrifugação por $10 \mathrm{~min}$ a $2.000 \mathrm{xg}$ para obtenção de soro e plasma (tubo sem anticoagulante, fluoreto de sódio e citrato de sódio).

No Hospital São Vicente, os testes foram realizados em até 4 horas após a coleta, com manutenção em temperatura ambiente. Por outro lado, as duplicatas das amostras foram enviadas em caixas isotérmicas, colocadas em estantes e acondicionadas com gelo reciclável, mantendo-se a temperatura média estável (13ํㅡ $\left.\mathrm{C} 23,5^{\circ} \mathrm{C}\right)$, conforme monitoramento da temperatura por chips registradores (Kooltrak) devidamente validados em nosso serviço (monitoração de temperatura durante o transporte de materiais biológicos da Associação Fundo de Incentivo à Psicofarmacologia [AFIP] - validação). O tempo médio do percurso desse transporte foi de aproximadamente 3 horas, e essas amostras foram processadas no período de 12 a 16 horas após a coleta. 


\section{Análise estatística}

Os dados estatísticos estão expressos em média \pm desvio-padrão (DP). A análise de concordância entre as duas medidas foi feita através do coeficiente de correlação intraclasse ${ }^{(4)}$ e também pela técnica de Bland-Altman ${ }^{(5)}$. Para os parâmetros hematúria, leucocitúria e cultura de amostra isolada de urina foram utilizados dois métodos de avaliação de concordância: a porcentagem de concordância simples e a estatística kappa ${ }^{(7)}$ (leva em consideração as concordâncias e as discordâncias).

\section{Limites usados para interpretação dos métodos}

\section{Coeficiente correlação intraclasse:}

- ausência de correlação: <0,25;

- correlação fraca a moderada: entre 0,25 e 0,5;

- correlação moderada a boa: entre 0,5 e 0,75;

- correlação boa a excelente: > 0,75.

\section{Estatística kappa}

- ausência de concordância: < 40\%;

- concordância moderada: entre $40 \%$ e $60 \%$;

- concordância moderada a boa: entre $60 \%$ e $80 \%$;

- concordância boa a excelente: > 80\%.

\section{Resultados}

Na Tabela 1 estão descritos a média e os DPs, correlação intraclasse e a concordância dos resultados dos analitos realizados no local (Jundiaî) e à distância (São Paulo).

A concordância entre as análises realizadas nos dois locais (Jundiaí e São Paulo) foi classificada em relação à correlação intraclasse como: boa/excelente: $>0,75$; moderada/boa: 0,5 a 0,75; fraca/moderada: 0,25 a 0,5; ausência de correlação: $<0,25$.

Entre os 29 analitos descritos na Tabela 1 observa-se

Tabela 1 Médias e desvio-padrão, correlação intraclasse e concordância dos analitos realizados

\begin{tabular}{lcccc}
\hline Analito & Média (DP) Jundiá & Média (DP) São Paulo & Correlação intraclasse & Concordância \\
Bilrrubina total & $0,8 \pm 0,6$ & $0,9 \pm 0,6$ & 0,99 & Boa/excelente \\
Cálcio & $9,3 \pm 0,5$ & $9,4 \pm 0,3$ & 0,67 & Moderada/boa \\
CK & $66 \pm 21,6$ & $84,6 \pm 28,8$ & 0,88 & Boa/excelente \\
CK-MB & $14,9 \pm 7,9$ & $20 \pm 7,7$ & 0,88 & Boa/excelente \\
Colesterol & $202 \pm 46,2$ & $226,7 \pm 56,9$ & 0,96 & Boa/Excelente \\
Creatinina & $1 \pm 0,2$ & $1 \pm 0,2$ & 0,87 & Boa/Excelente \\
LDH & $380,9 \pm 127,9$ & $404,2 \pm 149,7$ & 0,97 & Boa/excelente \\
Fosfatase alcalina & $112,1 \pm 32,9$ & $114,8 \pm 30,1$ & 0,99 & Boa/excelente \\
Fósforo & $3,4 \pm 0,4$ & $3,5 \pm 0,5$ & 0,71 & Moderada/Boa \\
GGT & $26,7 \pm 6,1$ & $28,8 \pm 6,3$ & 0,9 & Boa/excelente \\
Glicose & $102,7 \pm 49,7$ & $107 \pm 56$ & 0,98 & Boa/excelente \\
Magnésio & $1,6 \pm 0,2$ & $2 \pm 0,2$ & 0,62 & Moderada/Boa \\
Potássio & $4,5 \pm 0,4$ & $4,6 \pm 0,3$ & 0,77 & Boa/excelente \\
TGO & $22,3 \pm 6,3$ & $22,9 \pm 7,5$ & 0,93 & Boa/excelente \\
TGP & $18,3 \pm 6,4$ & $15 \pm 6$ & 0,84 & Boa/excelente \\
Triglicérides & $157,7 \pm 52,8$ & $161 \pm 58,4$ & 0,91 & Boa/excelente \\
Uréia & $33,8 \pm 11,4$ & $40,2 \pm 11,5$ & 0,76 & Boa/excelente \\
Eritrócitos & $4,7 \pm 0,6$ & $4,9 \pm 0,7$ & 0,91 & Boa/excelente \\
Hematócrito & $40,2 \pm 4,8$ & $40 \pm 4,8$ & 0,98 & Boa/excelente \\
Leucócitos & $6,5 \pm 2,2$ & $6,4 \pm 2,4$ & 0,99 & Boa/excelente \\
Linfócitos & $26,2 \pm 8,2$ & $29,4 \pm 7,6$ & 0,85 & Boa/excelente \\
Plaquetas & $251 \pm 72$ & $255,4 \pm 85,8$ & 0,93 & Boa/excelente \\
& & &
\end{tabular}




\begin{tabular}{lcccc} 
Segmentados & $62 \pm 9,1$ & $61 \pm 8,6$ & 0,68 & Moderada/boa \\
VHS & $12,2 \pm 15,6$ & $14 \pm 13,8$ & 0,97 & Boa/excelente \\
Fibrinogênio & $362,3 \pm 115,8$ & $378,2 \pm 103,4$ & 0,91 & Boa/excelente \\
RNI/TP & $1 \pm 0,1$ & $1,1 \pm 0,1$ & 0,3 & Fraca/Moderada \\
Relação TTPa & $1,08 \pm 0,1$ & $1,08 \pm 0,07$ & 0,51 & Moderada/boa \\
pH da urina & $6,1 \pm 0,6$ & $6 \pm 0,7$ & 0,86 & Boa/excelente \\
Densidade da urina & $1020,1 \pm 6,5$ & $1020,3 \pm 8,3$ & 0,81 & Boa/excelente \\
\hline
\end{tabular}

DP: desvio-padrão; CK: creatinoquinase; CK-MB: fração MB da creatinofosfoquinase; LDH: desidrogenase lática; GGT: gama-glutamiltransferase; TCO: transaminase glutâmico-oxalacética; TCP: transaminase glutâmico-pirúvica; VHS: velocidade de hemossedimentação; TTPa: tempo parcial de tromboplastina ativada. que $23(79,3 \%)$ apresentaram concordância boa a excelente, cinco $(17,2 \%)$ moderada a boa e um $(3,5 \%)$ fraca a moderada.

\section{Uroculturas}

Comparando-se os resultados das culturas de amostras isoladas de urina realizadas em Jundiaí e São Paulo, podemos observar que, das 25 culturas, houve concordância em 22 casos, sendo sete positivas e 15 negativas. Nos três casos não concordantes observaram-se um caso de positividade em Jundiaí e dois casos em São Paulo. A Tabela $\mathbf{2}$ mostra estes dados.

\section{Leucocitúria}

Com relação à urina $\mathrm{I}$, os resultados e a concordância da leucocitúria encontrada nas urinas, em amostras isoladas realizadas entre Jundiaí e São Paulo, observou-se que dos 16 casos analisados houve concordância total em 14, sendo quatro com leucocitúria e 10 sem ela. Apenas dois casos foram discordantes, porém com valores limítrofes.

\section{Hematúria}

Quanto aos resultados e à concordância da hematúria encontrada nas urinas, em amostras isoladas realizadas entre Jundiaí e São Paulo, podemos observar que, dos 18 casos analisados, houve concordância total em 17 , sendo três com hematúria e $15 \mathrm{sem}$. Apenas um caso foi discordante, porém com valores limítrofes.

\section{Discussão}

Os laboratórios estão sujeitos às influências externas, as quais podem ter um impacto na forma como desempenham seu trabalho. Tendo em vista as características atuais dos laboratórios e particularmente do nosso serviço, submetido às pressões econômicas cada vez maiores que este novo modelo econômico universal impõe, temos uma grande centralização de trabalho com um número cada vez maior de amostras processadas. O papel de um sistema de controle da qualidade efetivo nesses laboratórios é garantir não só que erros medicamente (clinicamente) significativos sejam detectados, mas também que falsas rejeições de amostras ocorram. Esses problemas, se não solucionados, não só implicam perdas eco-
Tabela 2

Método de Avaliação
Analito

Hematúria

Leucocitúria

Urocultura

\section{Porcentagem de concordância: hematúria, leucocitúria e urocultura}

Porcentagem de concordância

$94 \%$

Boa a excelente

$87,5 \%$

Boa a excelente

$88 \%$

Boa
Kappa

$81 \%$

Boa a excelente

$71 \%$

Boa

$73 \%$

Boa 
nômicas, mas também atraso de resultados e, principalmente, na fidelidade dos exames ${ }^{(1)}$.

Embora tenhamos uma fase pré-analítica dos exames colhidos nos postos periféricos, totalmente controlada no que diz respeito a coleta e condições de transporte (acondicionamento, tempo, temperatura, etc.), só poderemos ter certeza de que o processo pode ser validado, e portanto aceito, se conseguirmos demonstrar que os resultados não sofreram alterações medicamente significativas.

Para tanto, escolhemos um de nossos postos, o qual está localizado a maior distância e dispõe de condições laboratoriais comparáveis com a central, isto é, os mesmos aparelhos e reagentes e com pessoal técnico igualmente qualificado e treinado.

As amostras foram colhidas de forma aleatória, independente de sexo, idade ou estado patológico, no sentido de termos o maior número possível de valores normais e patológicos. Essa variabilidade não implica absolutamente análise dos resultados, uma vez que comparamos as amostras com elas mesmas, além de, ao mesmo tempo, nos permitir avaliar o comportamento de possíveis alterações em situações normais e patológicas.

No que diz respeito a reagentes e equipamentos utilizados, praticamente foram idênticos.

A análise estatística por nós adotada foi o coeficiente de correlação intraclasse ${ }^{(4,5)}$, método bastante atual e apreciado nos periódicos de grande impacto científico, por ser extremamente rigoroso para essa modalidade de variáveis. Para se ter uma melhor avaliação do rigor dessa análise basta observarmos resultados, como, por exemplo: cálcio: 9,3 3 $0,5 / 9,4 \pm 0,3$ que resultou num coeficiente de correlação intraclasse de apenas 0,67 , configurando uma concordância apenas moderada/boa. Não resta dúvida de que esses resultados, do ponto de vista da prática laboratoria|(15), são praticamente idênticos. Se analisarmos o único caso com concordância classificada como fraca/moderada, RNI/tempo de protrombina (TP), cujos valores são $1 \pm 0,1 / 1,1 \pm$ 0,1 , com um coeficiente de correlação intraclasse de 0,3 , mais uma vez temos que admitir que esses resultados são praticamente idênticos na rotina laboratorial. Assim podemos realmente constatar a potência e a rigidez do método analítico utilizado ${ }^{(6,8,14,18,21)}$.

Mesmo com este caso extremo, podemos dizer que todos os analitos dosados mostraram concordâncias aceitáveis quando realizados nesses dois locais diferentes no que diz respeito a transporte, acondicionamento e tempo de realização do exame.
As uroculturas mostraram concordância de $88 \%$. Em apenas três casos tivemos discordâncias. Em um deles curiosamente houve crescimento de flora mista no laboratório onde a amostra foi colhida, mostrando-se totalmente negativa no laboratório central (São Paulo). Analisando outros parâmetros desses casos, como leucocitúria paralela (ausente), teste do nitrito (negativo) e número de colônias $(<40.000 \mathrm{col} / \mathrm{ml}$ ), podemos dizer que houve contaminação da amostra na coleta no laboratório de Jundiaí, sendo esse fato não raro e bastante conhecido na prática laboratorial, o que implicaria nova coleta de urina ${ }^{(11)}$.

Nos outros dois casos houve discordância parcial, isto é, crescimento bacteriano, sendo em um deles flora mista em Jundiaí e gram-positivo em São Paulo; no outro houve uma ocorrência ao contrário, ou seja, crescimento de Klebsiella pneumoniae em Jundiaí e flora mista em São Paulo. No primeiro caso, a presença de flora mista já importaria, na nossa rotina, em nova coleta; e o crescimento de gram-positivo, não-Staphilococcus saprophyticus ou Enterococcus sp., também resultaria em nova coleta. Esta conduta é cautelosa e tem sido uma prática adotada por nós a fim de minimiza os problemas de coleta, tão presentes nos exames microbiológicos. A ausência de leucocitúria paralela requereria repetição do exame com nova coleta em Jundiaí, e, em São Paulo, por duas razões: flora mista e ausência de leucocitúria. Desta forma, não houve interferência do transporte nestes raros casos de uroculturas, mas sim da coleta de urina, um problema crônico no laboratório de análises clínicas. Portanto, podemos dizer que não houve alteração significativa nas uroculturas ${ }^{(12)}$.

Com relação às leucocitúrias, a discordância observada em dois casos, respectivamente 10.000/8.500 e 5.000/10.000, encontra-se nos valores limítrofes, pois consideramos leucocitúria $\geq 10.000$. Se considerássemos a leucocitúria para valores $>10.000$, não teríamos nenhuma discordância do ponto de vista prático.

O mesmo acontece com as hematúrias, porém em menor escala. Apenas um caso mostrou resultado discordante no que diz respeito aos valores de referência: $11.000 / 8.000$, mas também podemos observar que são valores extremamente próximos e limítrofes ${ }^{(11)}$.

Com relação aos demais parâmetros analisados em amostra isolada de urina ( $\mathrm{pH}$ e densidade), conforme mostra a Tabela 1, a concordância foi boa/excelente, dispensando qualquer comentário.

Por último, mas não com menos relevância, devem-se considerar dois aspectos fundamentais na análise de resultados laboratoriais ${ }^{(14)}$ : O primeiro diz respeito ao erro total dos exames laboratoriais, que se relaciona, por sua vez, com 
as variáveis quanto ao desempenho do ensaio: exatidão e precisão (acurácia e reprodutibilidade), cujo valor mínimo gira em torno de $5 \%$ na maioria dos ensaios, bem como da variação biológica dos diferentes analitos, que pode cursar com valores médios de aproximadamente $15 \%(10,16)$. Diante destes fatos eventuais, podemos constatar que a variação observada nas dosagens referidas neste trabalho encontra-se bem abaixo destes valores, o que nos permite validar estes resultados. O segundo aspecto que deve ser ressaltado é que, além das variações de sensibilidade, especificidade, exatidão e precisão, inerentes ao processo metodológico, não devemos esquecer o valor preditivo de cada resultado quando levamos em consideração, ademais dos parâmetros inerentes ao laboratório, a prevalência das doenças ${ }^{(17)}$.
Este trabalho de validação do processo pré-analítico de amostras colhidas a distância e enviadas ao laboratório, embora nos deixe convencidos de que os procedimentos por nós adotados preenchem os requisitos da qualidade, não dispensa a monitoração constante, em períodos predeterminados, no sentido de garantir a qualidade e, se possível, melhorá-la cada vez mais.

\section{Conclusão}

O sistema de transporte realizado pelo laboratório de grande porte e o tempo decorrido da coleta até a realização dos exames não alteraram significativamente os resultados dos parâmetros pesquisados.

\section{Referências}

1. BADRICK, T. Quality leadership and quality control. Clin Biochem Rev ,v. 24, p. 81-93, 2003.

2. BARHAM, D. et al. An improved color reagent for the determination of blood glucose by the oxidase system. Analyst, v. 97, p. 142-5, 1972.

3. BERG, B. et al. Stabilty of serum and blood constituents during mail transport. Scand J Clin Lab, v. 41, p. 45131, 1981

4. BLAND, J. M. et al. A note on the use of the intraclass correlation coefficient in the evaluation of agreement between two methods of measurement. Comput Biol Med, v. 20, n. 5, p. 337-40, 1990.

5. BLAND, J. M. etal. Statistical methods for assessing agreement between two methods of clinical measurement. Lancet, v. 1 , n. 8476 , p. 307-10, 1986

6. CARAWAY, V. T. Chemical and diagnostic specifity of laboratory tests. Am J Clin Path, v. 37, p. 445-64, 1962.

7 COHEN, J. A coefficient of agreement for nominal scales. Educ Psychol Mean, v. 20, p. 37-46, 1960.

8. COLE, T. G.; KLOTZSCH, S. G.; MCNAMURA, J. Meassurement of triglyceride concentration. In: RIFAI, N.; WARNICK, G. R.; DOMINICZAK, M. H. (eds.). Handbook of Lipoprotein Testing. Washington: AACC Press, 1997. p. 115-26.

9. DYBKOER, R. Quality assurance, acreditation and certification: needs and possibilities. Clin Chem, v. 40, p. 1416-20, 1994.

10 ENDRES, D. B.; RUDE, R. K. Mineral and bone metabolism. In: BURTIS, C. A.; ASHWOOD, E. R. (eds.). Tietz Textbook of Clinical Chemistry. 3. ed. Philadelphia: W.B Saunders Company, 1999. p. 1395-457.

11. GRAFF, S. A. Handbook of routine urinalyses. Philadelphia: J. B. Lippicott Company, 1983.

12. GUDER, W. G. et al. Amostras: do paciente para o laboratório - O impacto das variáveis pré-analíticas sobre a qualidade dos resultados de laboratório. São Paulo: Câmara Brasileira do Livro, 1996.

13. HANTGAN, R. R. et al. Fibrinogen structure and physiology. In: SCHMAIER, A. H. Hemostasis and trombosis: basic principles and clinical practice. Philadelphia: J.B. Lippincott Company, 1987. p. 269-88.

14. HENRY, R. J. Clinical chemistry principles and tecnics. 2. ed. New York: Harper and Row Publisher, 1974. p. 550.

15. QUICK, A. J. Fisiología y patología de la hemostasis. Buenos Aires: Ed. El Ateneo, 1952

16. RIOS, C. et al. Current databases on biologic variation: pros, cons and progress. Scand J Clin Lab Invest, v. 59, p. 491-500, 1999.

17. STATLAND, B. E. et al. Effects of preanalytical factors on the intraindividual variation of analytes inthe blood of healthy subjects: considerations of preparation of the subject an time of venipuncture. Crit Rev Clin Lab Sci, v. 8, p.105-44, 1977

18 SHAW, L. M. et al. International Federation of Clinical Chemistry, (IFCC), Scientific Committee, Analytical Section. IFCC methods for the meassurement of catalytic concentration of enzymes. Part 4. IFCC method for gamma-glutamyltransferase. J Clin Chem Clin Biochem, v. 21, p. 633-46, 1983

19. TIETZ, N. Fundam of Clin. Chem. Philadelphia: W.B. Saunders Co., 1986.

20. TIETZ, N. et al. Method for alkaline phosphatase. J Clin Chem Clin Biochem, v. 21, p. 731-48,1983.

21. WINSTEN, S. Standard methods in clinical chemistry 5. New York: Academic Press, 1965. p. 3.

22. WINTROBE, M. M. Hematología clínica. 3. ed. InterMédica, 1969

Endereço para correspondência

Alexandre Gabriel |r.

Rua Marselhesa, 500 - $7^{\circ}$ andar

CEP 04060-020 - São Paulo-SP

Tel: (11) 5908-7000 - R 6011

e-mail: alexandre@afip.com.br

e-mail: cristina@afip.com.br 